\title{
Erratum
}

\section{Thoughtful doctors: Not immune, but resistant to danger}

Response to 'Medicine in Danger?' by Gerben Meynen and JaccoP.H. Verburgt, Medicine, Health Care and Philosophy 2007 (doi: 10.1007/s11019-007-9067-1)

\section{Iain Brassington}

CSEP/School of Law, University of Manchester, Oxford Road, Manchester, M13 9PL, UK (Phone: + 44-161-4754728;

E-mail: iain.brassington@manchester.ac.uk)

Erratum to: Med Health Care and Philos (2007)

DOI 10.1007/s11019-007-9077-z

In the subtitle of this article the name of one of the authors has been misspelled. The subtitle should read:

Response to 'Medicine in Danger?' by Gerben Meynen and JaccoP.H. Verburgt, Medicine, Health
Care and Philosophy 2007 (doi: 10.1007/s11019007-9067-1).

The online version of the original article can be found under doi: 10.1007/s11019-007-9077-z. 